\title{
High Flow Nasal Cannula Therapy in Children with Acute Respiratory Insufficiency in the Pediatric Intensive Care Unit of a Resource-limited Country: A Preliminary Experience
}

\author{
Bushra Saeed ${ }^{1}$, Asim Azim², Anwar Ul Haque $^{3}$ and Qalab Abbas ${ }^{4}$ \\ ${ }^{1}$ Pediatric ICU, Children's Hospital, Lahore, Pakistan \\ ${ }^{2}$ Pediatric ICU, King Faisal Specialist Hospital and Research Centre, Riyadh, Saudi Arabia \\ ${ }^{3}$ Pediatric ICU, The Indus Hospital, Karachi, Pakistan \\ ${ }^{4}$ Department of Pediatrics and Child Health, The Aga Khan University Hospital, Karachi, Pakistan
}

\begin{abstract}
A retrospective study was performed in children (aged one month - 16 years) receiving HFNC to determine the frequency, efficacy and adverse effects of high flow nasal cannula (HFNC) therapy in the pediatric intensive care unit (PICU), from January to December 2017. Treatment failure was defined as clinical deterioration on HFNC therapy such that mechanical ventilation (MV) was required. Clinical parameters before and after HFNC were assessed using repeated measures analysis of variance. A total of 120 patients received HFNC therapy (21\% of total admissions). Primary diagnosis were respiratory disease (50\%), central nervous system diseases (14.2\%), sepsis (10.8\%), and postoperative care (10\%). Mean duration of HFNC was 27.5 \pm 19.7 hours and mean PICU length of stay was $6 \pm 6$ days. Pneumothorax developed in four patients. MV was required in 28 patients, and subsequently, 15 deaths occurred in that group. HFNC is a frequently used, safe and effective therapy for children requiring respiratory support in PICU.
\end{abstract}

Key Words: Respiratory insufficiency, Non-invasive ventilation, Paediatric intensive care unit.

How to cite this article: Saeed B, Azim A, Haque AU, Abbas Q. High Flow Nasal Cannula Therapy in Children with Acute Respiratory Insufficiency in the Pediatric Intensive Care Unit of a Resource-limited Country: A Preliminary Experience. J Coll Physicians Surg Pak 2021; 31(01):110-112.

Respiratory illnesses are one of the leading causes for pediatric intensive care unit (PICU) admission (26.3\%). ${ }^{1}$ Respiratory support in PICU has evolved from predominantly mechanical ventilation (MV) to non-invasive ventilation. This has markedly reduced complications related to invasive mechanical ventilation. ${ }^{2,3}$ Heated, humidified, high-flow nasal cannula (HFNC) is a relatively new method of respiratory support. ${ }^{4} \mathrm{HFNC}$ washes out the carbon dioxide-rich gas in a portion of the anatomical dead space and potentially provides positive airway pressure. Humidification saves energy spent warming and enables better tolerance by decreasing the risk of nasal trauma. ${ }^{5}$ Previous clinical studies using HFNC therapy have shown a reduction in intubation rates in critically ill infants in PICU with a better safety profile. ${ }^{3,4,6}$

Correspondence to: Dr. Qalab Abbas, Department of Pediatrics and Child Health, The Aga Khan University Hospital, National Stadium Road, Karachi, Pakistan E-mail: qalababbas@gmail.com

Received: December 03, 2019; Revised: February 29, 2020; Accepted: May 11, 2020

DOI: https://doi.org/10.29271/jcpsp.2021.01.110
We describe use of HFNC in our PICU. This study will pave the path for larger studies on use of HFNC in children with acute respiratory distress.

Retrospective review of medical records of children (aged one month - 16 years) admitted in PICU of the Aga Khan University Hospital and received HFNC, was done from January to December 2017 after ethical approval (2019-1036-2634). The decision to start HFNC was based on patients' clinical condition [respiratory distress defined as increased respiratory rate, increased work of breathing, oxygen saturation as per standard pediatric advanced life support (PALS) guidelines], hemodynamic stability (age-appropriate normal heart rate, perfusion and blood pressure as per PALS criteria), normal Glasgow coma scale (GCS) and oxygen saturation $\left(\mathrm{SaO}_{2}\right)$ and attending physician discretion. Patients with $\mathrm{SaO}_{2}<88 \%$ on pulse oximetry, GCS $<12$, and hemodynamic instability were not provided HFNC. HFNC was provided at the maximum rate of 2 litres/kilogramme body weight/minute, through Optiflow ${ }^{\circledR}$ system with age appropriate nasal cannulas (Fisher and Paykel Healthcare). HFNC was switched to $\mathrm{O}_{2}$ by nasal prongs, if patient was at $<40 \%$ $\mathrm{FiO}_{2}$ for more than 6 hours with stable vital signs and work of breathing, and waslabelled HFNC success. 
Table I: Comparison of variables between high flow nasal cannula success and failure.

\begin{tabular}{|c|c|c|c|}
\hline & $\begin{array}{l}\text { High flow nasal cannula failure } \\
\text { (intubated) } \\
n=28\end{array}$ & $\begin{array}{l}\text { High flow nasal cannula success } \\
\text { (non-intubated) } \\
n=92\end{array}$ & $\begin{array}{l}\text { Independent t-test / } \\
\text { Chi-square test } \\
\text { p-value }(95 \% \mathrm{CI})\end{array}$ \\
\hline Heart rate & Mean \pm SD* & Mean \pm SD & \\
\hline 0 hours (before start of HFNC) & $154 \pm 21$ & $145.6 \pm 21$ & 0.11 \\
\hline At 2 hours of HFNC & $135 \pm 13$ & $125.38 \pm 21$ & 0.034 \\
\hline At end of HFNC & $127.18 \pm 26$ & $115.11 \pm 19$ & 0.01 \\
\hline \multicolumn{4}{|l|}{ Respiratory rate } \\
\hline 0 hours (before start) & $46.7 \pm 13$ & $49.30 \pm 12$ & 0.35 \\
\hline 2 hours & $39.6 \pm 14$ & $35.37 \pm 8$ & 0.066 \\
\hline End of HFNC & $35.82 \pm 18$ & $28.67 \pm 8$ & 0.003 \\
\hline $\mathrm{SaO}^{2} / \mathrm{FiO}^{2}$ ratio & $210 \pm 63.28$ & $217.56 \pm 51.70$ & 0.59 \\
\hline $\begin{array}{l}\text { Gender: } \\
\text { Male } \\
\text { Female }\end{array}$ & $\begin{array}{l}21 \\
7\end{array}$ & $\begin{array}{l}53 \\
39\end{array}$ & $0.09,(0.85-5.71)$ \\
\hline $\begin{array}{l}\text { Admission source: } \\
\text { Emergency } \\
\text { Inpatient } \\
\text { Operating room } \\
\text { Cardiac ICU }\end{array}$ & $\begin{array}{l}20 \\
7 \\
0 \\
1\end{array}$ & $\begin{array}{l}53 \\
30 \\
8 \\
1\end{array}$ & 0.23 \\
\hline $\begin{array}{l}\text { Reason for admission: } \\
\text { Acute respiratory distress } \\
\text { acute respiratory failure } \\
\text { post-op care } \\
\text { Others (for monitoring) }\end{array}$ & $\begin{array}{l}3 \\
22 \\
0 \\
3\end{array}$ & $\begin{array}{l}38 \\
32 \\
12 \\
10\end{array}$ & 0.001 \\
\hline $\begin{array}{l}\text { Comorbids: } \\
\text { Yes } \\
\text { No }\end{array}$ & $\begin{array}{l}16 \\
12\end{array}$ & $\begin{array}{l}49 \\
43 \\
\end{array}$ & $0.72(0.49-2.75)$ \\
\hline $\begin{array}{l}\text { Diagnosis: } \\
\text { Central nervous system diseases } \\
\text { Cardiovascular diseases } \\
\text { Respiratory diseases } \\
\text { Gastrointestinal diseases } \\
\text { Infections } \\
\text { Malignancy } \\
\text { Surgical } \\
\text { Miscellaneous }\end{array}$ & $\begin{array}{l}3 \\
5 \\
14 \\
1 \\
3 \\
0 \\
1 \\
1\end{array}$ & $\begin{array}{l}14 \\
6 \\
46 \\
0 \\
10 \\
1 \\
11 \\
4\end{array}$ & \\
\hline $\begin{array}{l}\text { Survival: } \\
\text { Yes } \\
\text { No }\end{array}$ & $\begin{array}{l}19 \\
9\end{array}$ & $\begin{array}{l}86 \\
6\end{array}$ & $0.001(0.047-0.46)$ \\
\hline
\end{tabular}

If a patient had $\mathrm{SaO}_{2}<88 \%$ on $\mathrm{HFNC}, \mathrm{FiO}_{2}$ requirements $>70 \%$, respiratory distress or hemodynamic instability, HFNC treatment was regarded as failure and MV was instituted. Patients were also observed for development of complication (pneumothorax) detected on chest X-ray.

Data collection included demographic, clinical, and HFNC details. Chi-square / T-test were applied to compare HFNC success versus failure. A p-value of $<0.05$ was taken as significant.

A total of 120 patients met the inclusion criteria, making $21 \%$ of total PICU admissions. The primary diagnosis was respiratory system diseases $(60,50 \%)$, central nervous system diseases $(17,14.2 \%)$, sepsis $(13,10.8 \%)$, postoperative care $(12,10 \%)$ and miscellaneous (two patients with acute kidney injury and severe diabetic ketoacidosis each and one patient with severe malnutrition).

Mean HFNC duration was $27.5 \pm 19.7$ hours, while mean PICU length of stay was $6 \pm 6$ days. Twenty-eight patients
(23.3\%) failed HFNC and required MV. Complication (pneumothorax) developed in four (3.3\%) and all survived. Mean heart rate and respiratory rate decreased significantly in all patients after two hours of HFNC therapy ( $p<0.05$, Table I). This difference was more pronounced in patients in whom HFNC was successful as compared to patients who failed HFNC therapy (Table I). The $\mathrm{SaO}_{2} / \mathrm{FiO}_{2}$ ratio was same in both groups $(p=0.59)$. Fifteen $(12.5 \%)$ patients died, underlying cause was acute respiratory distress syndrome (ARDS) in seven, acute heart failure in four, sepsis in two, and acute leukemia with relapse in one.

HFNC is being increasingly used in children for a variety of conditions. ${ }^{2}$ Recent studies have shown HFNC to be effective in infants with bronchiolitis, requiring less escalation of therapy compared to standard therapy. ${ }^{6}$

Escalation to MV (23\%) in this study was higher than in previous studies of $8-18 \% \cdot{ }^{3,6}$ Amongst patients who failed HFNC, there were 15 deaths and failure of HFNC could be due to the severity of presenting disease. However, 
mechanical ventilation was not warranted at the start of treatment in any of the patients and so there was clinical equipoise as to the use of HFNC at this stage of disease evolution, allowing us to determine our own criteria for its use. This study did not consider the diagnosis-specific failure rate.

Pneumothorax was the main complication observed in this study. Previous report show frequency of $<1 \%$ of development of pneumothorax with HFNC. ${ }^{3,6}$ Pneumothorax on HFNC develops with severe underlying lung disease or due to formation of seal around the nasal cannula due to thick secretions or inappropriate nasal cannula size.

Pneumothorax was small in all these patients with no hemodynamic instability and spontaneous resolution in three, one required chest drain insertion. It could be related to underlying disease process but further exploration into the cause of pneumothorax was not possible because of type of study design.

Heart rate and respiratory rate improved significantly within two hours of start of HFNC therapy in all the patients, and this difference was significant in patients with HFNC success compared to those who failed the intervention. This means that clinical status assessment after two hours of starting HFNC therapy is important and can be a predictor of HFNC therapy success. Further studies must be performed to explore this. $\mathrm{SaO}_{2}$ and $\mathrm{FiO}_{2}$ ratio (a marker of severity of hypoxia and disease) were similar in the both the groups.

The study has limitations of being a single centre, retrospective and small sample size. Further studies may identify reliable cardiorespiratory and diagnostic predictors of therapy failure. Despite that, HFNC is frequently used, safe and effective therapy for children requiring respiratory support in PICU.

\section{ETHICAL APPROVAL:}

This study was exempted from full ethical approval because of observational nature of this study by the Ethical Review Committee of the Aga Khan University (Ref \#2019-1036-2634).

\section{PATIENTS' CONSENT:}

Because of the observational nature of the study which didn't involve any patients' interaction/intervention, the need for consent was waived by the Ethical Review Committee.

\section{CONFLICT OF INTEREST:}

The authors declared no conflict of interest.

\section{AUTHORS' CONTRIBUTION:}

BS, AA: Wrote protocol along with QA and AH guidance, collected data, and contributed in manuscript writing.

$\mathrm{QA}, \mathrm{AH}$ : Conceived the idea and contributed in manuscript writing.

QA: Analysed data.

All approved final form of the manuscript.

\section{REFERENCES}

1. Namachivayam P, Shann F, Shekerdemian L, Taylor A, van Sloten I, Delzoppo C, et al. Three decades of pediatric intensive care: Who was admitted, what happened in intensive care, and what happened afterward. Pediatr Crit Care Med 2010; 11(5):549-55. doi: 10.1097/PCC.0b013 e3181ce7427

2. Xu XP, Zhang XC, Hu SL, Xu JY, Xie JF, Liu SQ, et al. Non-invasive ventilation in acute hypoxemic nonhypercapnic respiratory failure: A systematic review and meta-analysis. Crit Care Med 2017; 45(7):e727-e33. do.'i: 10.1097/CCM. 0000000000002361.

3. Clayton JA, McKee B, Slain KN, Rotta AT, Shein SL. Outcomes of children with bronchiolitis treated with high-flow nasal cannula or noninvasive positive pressure ventilation. Pediatr Crit Care Med 2019; 20(2):128-35. doi: 10.1097/PCC.0000000000001798.

4. Morris JV, Kapetanstrataki M, Parslow RC, Davis PJ, Ramnarayan $P$. Patterns of use of heated humidified high-flow nasal cannula therapy in PICUs in the United Kingdom and republic of ireland. Pediatr Crit Care Me 2019; 20(3):223-32. doi: 10.1097/PCC.0000000000001805.

5. Liew Z, Fenton AC, Harigopal S, Gopalakaje S, Brodlie M, O'Brien CJ. Physiological effects of high-flow nasal cannula therapy in preterm infants. Arch Dis Child Fetal Neonatal Ed 2020; 105(1):87-93. doi: 10.1136/archdischild-2018316773.

6. Franklin D, Babl FE, Schlapbach LJ, Oakley E, Craig S, Neutze J, et al. A randomised trial of high-flow oxygen therapy in infants with bronchiolitis. N Engl J Med 2018; 378(12):1121-31. doi: 10.1056/NEJMoa1714855. 